\title{
Nanotechnology in Materials and Medical Sciences
}

\author{
R. Sathiyapriya ${ }^{1,2 *}$, V. Hariharan ${ }^{3}$, K.Prabakaran ${ }^{3}$, M.Durairaj ${ }^{1}$, V.Aroulmoji ${ }^{1,2 *}$ \\ ${ }_{1}^{1}$ Department of Physics, Mahendra Engineering College (Autonomous), Namakkal, Tamilnadu, India \\ ${ }^{2}$ Center for Research and Development, Mahendra Engineering Colleges, Namakkal District, Tamil Nadu, India \\ ${ }^{3}$ Department of Physics, Mahendra Arts and Science College (Autonomous), Namakkal,Tamilnadu, India
}

\begin{abstract}
Nanotechnology is nothing but a branch of technology smaller in size, lighter in weight, stronger in strength due to its large surface area to volume ratio. The applications of nanotechnology have been widely used by several industries globally, especially in the development of innovative products using novel materials in cosmetics, paints, ceramic, textile coatings and pharmaceuticals. Nanoparticles have been designed in different morphological structures at the microscopic level such as nanospheres, nanotubes, nanorods, nanowires, nanoplatelets, nanoflower, nanoparticles and nanoneedle. By bearing in mind the importance of Nano dimensional material, the present review article, therefore, focuses on the reviews of the advances and development of nanotechnology applications to cosmetics, paints, textile and medical research.
\end{abstract}

KEYWORDS: Nanotechnology, Nanoparticles, paints, textiles, ceramics, cosmetics

\section{INTRODUCTION}

Nanoscience and Technology deal with the materials within the dimension $1-100 \mathrm{~nm}$. Nano science gave a new pathway for new dimensions to basic science leading to a range of new technologies. Classical talk by Nobel Laureate Richard Feynman on December 29th, 1959 at Caltech, California Institute of Technology became the silver sword for the future of nanotechnology. His famous lecture titled, "There's Plenty of Room at the Bottom" became an invitation to discover a new field of physics called as Nanoscience and Technology. In 1990 Drexler quote: 'Nanotechnology is the principle of atom manipulation atom by atom, through control of the structure of matter at the molecular level. It is well known that Nanotechnology is broadly defined as the understanding and control of matter at dimensions of roughly 1-100 $\mathrm{nm}$, where unique phenomena enable novel applications. It entails the ability to build molecular systems with atom by atom precision, yielding a variety of Nano machines [1]. Nano science is nothing but manipulation of materials at atomic, molecular and macromolecular scales, where properties differ significantly from those at larger scale. Nanotechnologies deal with the design, characterization, production and application of structures, devices and systems by controlling shape and size at nanometer scale. The prefix nano is derived from Greek word dwarf. Technology means the building of useful thing from the scientific principles. Thus, nanotechnology means building useful things at $10^{-9}$ level. One nanometer $(\mathrm{nm})$ is equal to onebillionth of a meter, i.e., $10^{-9}$ level. A human hair is approximately $80,000 \mathrm{~nm}$ wide, and a red blood cell approximately $7000 \mathrm{~nm}$ wide. Due to their high surfaceto-volume ratio, metallic nanoparticles show unique physical, chemical and biological properties when compared with the macro scale. Hence, Nanoparticles (NP) play a vital role in research area in recent years [2]. Nanomaterials are classified as four divisions, (1) Quantum dots, Nanodots, Inorganic macromolecules, (2)Nanocrystals, Nanophases, Nanostructures, (Nanoparticles, Nanointermediates, Nanocomposites), (3) Nanorods, Nanoplatelets, Nanotubes, Nanofibrills,
Quantum wires (4) Nanoholes, Composite.

The term "Nanomaterials" covers materials in one dimension (thin films), two-dimension (nanofibers, nanowires, nanotubes, etc.) and three-dimension (nanopowders, nanocapsules, fullerenes, dendrimers, precipitates, colloids, quantum dots, nanostructured materials, nanoporous materials, etc.) $[3,4]$.Two principle factors cause the properties of nanomaterials to differ significantly from other materials: increased relative surface area and quantum effect. Properties of nanomaterials: Mechanical properties, Thermal properties, Biological properties, Optical properties, Chemical properties. Synthesis of nanoparticles include two main routes, they are Top-down method and Bottomup method. Top-down method include Mechanical milling/Ball milling, Chemical etching, Laser ablation, Sputtering. Bottom-up method include Chemical/Electrochemical method (Chemical precipitation, Electrochemical) [5-7], Vapor Deposition Method [Chemical vapor deposition (CVD), Physical vapor deposition (PVD)] [8-11], Atomic/Molecular Condensation [12], Sol-gel processes [13-16], Spray pyrolysis, Laser Pyrolysis, Aerosol Processes and Bioreduction Method.

In synthesis methods, Chemical synthesis is a popular approach for the production of NPs; however, it requires the use of toxic chemicals as reducing and/or capping agents $[17,18]$. In green methods, no toxic chemicals are used in the synthesis protocol [19]. The green method has proved to be better than the chemical methods due to slower kinetics, which offers a better control over crystal growth and reduced capital involved in production of nanoparticles [20]. In addition, the green synthesis of nanoparticles using microorganism [21-24] fungus [25], plants and plant extracts [26-30], has been suggested as possible eco-friendly alternatives to chemical and physical method. The use of plants in the synthesis of nanoparticles is quite rapid, low cost, eco-friendly and a single-step method for biosynthesis process [31].

Potential applications of nanoparticles have been exploited in various fields such as Biomedical devices, Drug-delivery, Flat-panel displays, Medical imaging, High- 
energy batteries, Sensors, Paints and pigments, Automobile components, Formable ceramics, High-power, magnets, Smart structures, CMP slurries, KE penetrators/warheads, Catalyst, Phosphors, Dielectrics, Fuel cells, Optical devices, Cutting tools, Cosmetics, Aerospace components etc., due to their novel properties $[32,33]$.

Nanometallic particles are used as an antimicrobial and/or sector of catalysis, conductive layers of screens, sensors or energetic materials. Nanoporous is used as aerogels for thermal insulation in the areas of electronics, optics and catalysis, bio-medical field for tracing or even implants type applications. Nanotubes are used as electrical conductive nanocomposites, structural materials, single-walled nanotubes used in conductive adhesives and connectors, ceramic applications, tyre and optic industries. Massive nanomaterials are used as hard coatings, structural components for the aerospace industry, automotive, pipes for oil and gas, sport or even anti-corrosion sector industries. Dendrimers are used in medical field (administration of drugs, rapid detection), cosmetic preparations. Quantum dots are used in optoelectronics (screens), photovoltaic cells, inks and paints for applications of type marking anti-counterfeiting. Fullerenes are used in sport materials, development of photovoltaic solar cells, used as hardening agents for the development of light weight materials and also several applications in health care sectors, used as excellent anti oxidants, anti viral agent, drug delivery and gene delivery, photo sensitizers in photo dynamic therapy and polymers with optical limiting properties (surface coating and phtotoconducting devices in particular for applications in artificial photosynthesis) $[34,35]$. Nanowires are used in the conductive layers of screens, solar cells and electronic devices [36]. This review covers the recent development on the applications of nanoparticles towards various areas of research.

\section{NANOPARTICLES IN MATERIAL SCIENCES \\ 2.1 Application of Nanoparticles in Cosmetics}

Varity types of nanoparticles are commonly used in cosmetic preparations especially in sunscreen lotion, moisturizers, nail polish, hair care products and makeup creams. In cosmetics formulation nanoparticles work as UV filters. Zinc oxide and titanium oxide nanoparticles have been used for a long time in sunscreen preparation because of its ability to absorb or scatter the sun's ultraviolet radiation and prevent sunburn. Nowadays, the size of the particle has been reduced over recent years from micro to nano which has led to sunscreens that visually blend better into the skin. Nanoemulsions are used in hair care products to encapsulate active ingredients and carry them deeper into hair shafts. The average size of nanoparticles used in UV filters is around $40 \mathrm{~nm}$. The European Commission is regularly updating the catalogue of nanomaterials used in cosmetic preparations [37]. Marcus Lau [38] demonstrated that the direct integration of Laser-generated nanoparticles can be used in transparent nail polishes. The method for integration of metal (gold, platinum, silver, and alloy) nanoparticles into varnishes is straight forward and gives access to nano doped polishes with optical properties, difficult to be achieved by dispersing powder pigments in the high-viscosity liquids. The used nanoparticles have no corona of residual chemicals or capping agents.
Regarding the use of nanoparticles in cosmetic formulations, some researchers had concern about the safety issue, when nanosilver is incorporated in cosmetic products they can easily penetrate through the skin. Due to their smaller size, nanoparticles can easily permeate through skin, then to the various organs which may damage the cell and DNA rendering to organ death [39]. As the human skin is semi permeable in nature, they will not allow nanomaterials passage through it easily. Some investigators concluded that nanoparticles incorporated cream does not penetrate through the skin [40]. In this, Kokura et al. reported that the silver nanoparticles do not easily penetrate on the human skin but when the barrier function of skin is disrupted, they can penetrate through the skin. The ratio of nanoparticles penetration is less than $2 \%$ and penetrates to $0.002-0.02 \mathrm{ppm}$. They confirmed that no toxicity was observed when the bulk metals were turned to trace element [41]. Nanoparticles ranging from 20 to $200 \mathrm{~nm}$ size cannot penetrate skin barrier until they are partially damaged, whereas nanoparticles with a diameter of less than $10 \mathrm{~nm}$ could reach deeper layer of stratum corneum [42] and $40 \mathrm{~nm}$ could reach only 5-8 $\mu \mathrm{m}$ into stratum corneum [43]. There are some specific nanoparticles like chromium, silver, $\mathrm{TiO}_{2}$, and $\mathrm{ZnO}$ which do not penetrate deeper than the stratum corneum [44].

Sonia et al [45] reported that the antimicrobial and antioxidant potentials of the biosynthesized colloidal zinc oxide nanoparticles are used for a fortified cold cream formulation. The zinc oxide nanoparticles ( $\mathrm{ZnO})$ were synthesized using Adhatoda vasica leaf extract and characterized. The antibacterial and antifungal activities of biosynthesized ZnO Nps were evaluated. The formulated $\mathrm{ZnO} \mathrm{Nps}$ infused cold cream showed microbicidal and antioxidant properties and also tested against clinical skin pathogens. The authors concluded that the nano-based cold cream exhibited significant inhibitory action against Candida sp.,.

\subsection{Nanoparticles in Paints Formulation}

It is to be noted that Nanomaterials play a vital role in existing properties of paints due to their large surface to volume ratio and their specific structural characteristics such as shape and size. Potential functional benefits and effects of nanomaterials in paints are mainly dependent on their material type: Titanium dioxide (anatase) functions as bactericidal, easy to clean, fire retardant, selfcleaning and thermal insulation. Self cleaning is due to hydrophilic property of titanium dioxide and thus it no longer needs regular cleaning because the water and dirt will not stick on it for longer. The photocatalytic property leads to the degradation of the binder by UV irradiation. Titanium dioxide (rutile) functions as bactericidal, fire retardant, self-cleaning and thermal insulation. Silicon dioxide functions as anti-graffiti, easy to clean, fire retardant, scratch resistance, thermal insulation and water repellent. When silicon dioxide added with polymeric resins, paints shows excellent abrasion properties. These properties of silicon dioxide nanomaterials should improve the macro and micro hardness, abrasion scratch and weather resistance. Silicon dioxide avoids the swelling and shrinking associated with temperature and humidity changes due to its excellent abrasion properties [46, 47]. Silver functions as bactericidal. Silver coating provides excellent antimicrobial properties against bacteria and human 
pathogens. From the above functionalities of nanomaterials titanium dioxide and silicon dioxide are more relevant nanomaterials for paint industries but silver, zinc oxide, aluminium oxide, cerium dioxide, copper oxide, and magnesium oxide are also under investigation $[48,49]$.

Bellotti et al [50] reported the incorporation of silver, copper and zinc oxide nanoparticles in indoor water borne paints. The antifungal activity using previously isolated fungi, Chatomium globasum and Alternaria alternate, on solid medium were evaluated. They concluded that the paint formulated with silver $(10 \mathrm{~nm})$ nanoparticles showed better results than other copper and zinc oxide.

Similarly, Angel Yedra et al [51] formulated paints with tailored electrical properties by incorporating multiwall carbon nanotubes (MWCNTs) in a commercial polymeric base paint in low content (below $3 \mathrm{wt} . \%$ ). The paint was sprayed on metallic and glass substrates and studied different parameters like thickness, adhesion, hardness, electrical conductivity and resistance to environmental degradation. The formulated paint showed good electrical conductivity values up to 8 orders of magnitude higher than the pristine paint and also shows significant improvements in their performance against environmental degradation.

\subsection{Application of Nanoparticles in Ceramics}

Nanoceramics have unique properties due to their molecular structure and size. The nanoceramics properties depend on: Delectric, Ferroelectric, Piezoelectric, Pyroelectric, Ferromagnetic, Magnetoresistive, Superconductive and Electro-optical [52].

Ceramics industries are widely used unique properties like strong, hard, and abrasion-resistant materials. Silicon nitrides are used to make mechanical tools like cutting, shaping, grinding, and sanding iron, nickel-based alloys, etc.

In electrical industries ceramics are used as insulators, semiconductors, and conductors. Different materials possess different functions which are given below:

$>\mathrm{Al}_{2} \mathrm{O}_{3}, \mathrm{SiC}+\mathrm{BeO}$ functions as insulators for IC substrate applications

$>\mathrm{BaTiO}_{3}$ functions as Dielectric for capacitor application

$>\mathrm{SiC}, \mathrm{LaCrO}_{3}, \mathrm{SnO}_{2}, \mathrm{ZnO}+\mathrm{Bi}_{2} \mathrm{O}_{3}$ functions as semiconductors for gas defector, thermistor, varistor application

$>\mathrm{ZnO}, \mathrm{SiO}_{2}$ functions as piezoelectricity for piezo lighter, piezo filter, surface wave transducer application

$>$ PZT functions as Pyroelectricity for IR detectors applications

$>$ PLZT functions as Ferroelectricity for optical shutter, optical memory applications

$>$ b-Al203, ZrO2 functions as Ionic conductors for Na-S battery, $\mathrm{O}_{2}$ sensor applications

$>\quad \mathrm{Y}_{2} \mathrm{O}_{2} \mathrm{~S}: \mathrm{Eu}, \quad \mathrm{ThO}_{2}: \mathrm{Nd}, \quad \mathrm{Al}_{2} \mathrm{O}_{3}: \mathrm{Cr}$ functions as Luminescence for cathode luminescence, IR laser applications

$>\mathrm{SiO}_{2}$ functions as Light guide for optical communication fiber applications

$>$ PLZT functions as Polarization for optical shutter applications

$>\mathrm{g}-\mathrm{Fe}_{2} \mathrm{O}_{3}, \mathrm{Zn} 1_{-} \mathrm{Mn}_{\mathrm{x}} \mathrm{Fe} 2 \mathrm{O} 4$ functions as Soft magnetism for magnetic tape applications
$>\mathrm{SrO}_{6} \mathrm{Fe}_{2} \mathrm{O}_{3}$ functions as Hard magnetism for magnet seal applications

In biomedical field ceramics are used to make implants for use within the body. Ceramic materials are well known for their biocompatibility property which will support bone cells and tissues. Some porous ceramic materials such as alumina, titania, zirconia will bind with bones and other natural tissues and these materials are used to make hip joints, dental caps, and bridges [53]. Rosanna et al [54] reported a new method for the fabrication of hydroxyapatite (HAp) sponges by using amino-acid-coated HAp nanoparticles dispersed within a viscous polysaccharide (dextran sulfate) matrix, and examined the usefulness of these materials for the viability and proliferation of human bone marrow stromal cells. They suggested the potential applications in cartilage or soft tissue engineering.

\subsection{Nanoparticles in Textiles}

One of the most important industries for consumer goods is textile industry worldwide generating textiles for clothing, household goods, furnishing and technical purposes. Nanomaterials play a vital role for adding or improving different functionalities of the textiles and also have an adverse effect on humans and environment [5860]. Nanomaterials have number of functionalities to textiles such as UV protection, breathability, conductive, antistatic properties, wrinkle resistance or resistance to stains, bacteria or fungi, dirt and water repellence depending on the material. Nanomaterials can be directly applied to the fibre surface or incorporated into fibre coatings (eg., polymers). These possible impacts may be reduced by selecting suitable nanomaterials and their careful integration in the fabric. Different nanomaterials have different functions depending on their specific property. $[55,56]$

Silver functions as an antimicrobial, antistatic, electrical conductivity, and self-cleaning. It also reduces microbial growth on the textile (clothing, household, and furnishing) by releasing silver ions, which will react on the surface of the fibre. Zinc oxide functions as abrasion resistance, antimicrobial, dirt repellent, photocatalytic, self-cleaning, UV-absorption, water repellent. Zinc oxide nano-rods considered as great for coating cotton fabric due to its super hydrophobic properties (i.e. waterrepellence). Silicon dioxide functions as abrasion resistance, active substance carriers, chemical resistance, dirt repellent, flame retardant, self-cleaning and water repellent. Hydrophobic property of silicon dioxide nanoparticles makes cotton surface water-repellent. Titanium dioxide functions as antimicrobial, dirt repellent, flame retardant, photocatalytic, self-cleaning, UVabsorption, water repellent. Aluminium oxide functions as abrasion resistance chemical resistance, flame retardant. Nanoclays functions as abrasion resistance, active substance carriers, flame retardant. CNT functions as abrasion resistance, antistatic, electrical conductivity, flame retardant and high tensile strength. Carbon black functions as antistatic and electrical conductivity. Carbon nanotubes (CNTs) enhance textiles and fibres with flameretardant properties, and also generate electrical conductivity [57]. Moustafa M.G. Fouda et al reported an excellent review on the usefulness of antibacterial modification of textiles using nanotechnology. This review mainly focused on conventional antimicrobial agents and 
their applications to textiles followed by inorganic nanostructured materials showed good antibacterial activity to textiles [58].

\subsection{NANOPARTICLES IN MEDICAL SCIENCES 2.5.1 Wound dressings}

The world's first commercially available nanosilver product was developed by Robert Burrell to treat various wounds in clinic, including burns, chronic ulcers, toxic epidermal necrolysis, and pemphigus. Recently, new antibacterial dressings are being fabricated for the promotion of wound healing and increasing antibacterial efficacy. Konop et al reviewed certain aspects of silver and silver Nanoparticles in wound care management. The authors reported simple history of silver, mechanism of silver action, antibacterial properties of silver nanoparticles, conjugation methods of AgNP with antibiotics, wound dressing materials containing silver and finally discussed the toxicity and applications of silver and silver nanoparticle dressings [59]. Burd et al [60] reported a comparative study of the cytotoxicity of silverbased dressings in monolayer cell, tissue explants, and animal. They examined five commercially available silverbased dressings namely Acticoat ${ }^{\mathrm{TM}}$, Aquacel ${ }^{\circledR} \mathrm{Ag}$, Contreet $\AA$ Foam, PolyMem $®$ Silver, Urgotul $₫ S S D$ and evaluated their cytotoxicity in a monolayer cell culture, a tissue explant culture model, and a mouse excisional wound model. The cytotoxicity was correlated with the silver released from the dressings as measured by silver concentration in the culture medium. The results show that silver dressings resulted in a significant delay of reepithelialization. In the mouse excisional wound model, Acticoat and Contreet Foam indicated a strong inhibition of wound re-epithelialization on the post wounding-day 7 .

Moreover, Singh \& Singh [61] studied the chitin membranes containing silver nanoparticles for wound dressing applications. Silver nanoparticles were synthesized by gamma irradiation at doses of $50 \mathrm{kGy}$ in the presence of sodium alginate as stabilizer. They tested the antimicrobial activity using Pseudomonas aeruginosa and Staphylococcus aureus to determine the antimicrobial efficiency of the chitin membranes containing $30,50,70$ and $100 \mathrm{ppm}$ nanosilver. The chitin membranes with 100 ppm nanosilver showed promising antimicrobial activity against common wound pathogens. Recently, Yang and Hu [62] reviewed the importance of antimicrobial silver absorbent wound dressings applied to exuding wounds. The authors focused on the antimicrobial absorbent dressings treated with silver ions or silver particles. The methods of dispersing silver in dressings include coating or spraying silver-containing solution on the wound dressing surface, padding the wetted dressing with pressure, embedding silver nanoparticles in non-woven fibers was reviewed. When silver dressings absorb exudate from wounds, the antimicrobial silver will be activated and then breaks down the bacterial cell wall to kill the bacterium. Silver foam dressings and silver alginate dressings are the most popular antimicrobial absorbent dressings, producing in many health care companies.

\subsubsection{Catheters}

Silver is known for its antimicrobial activity since ancient times. Research has been conducted to investigate nanoparticles as antimicrobial materials for coating catheters. Medical catheters are prone to bacterial infection, which can rapidly spread to the wound and its surrounding, and lead to serious complications. Nanoparticles can reduce the bacterial infection and complications after surgery, due to their superior antimicrobial properties. Hence, nanoparticles have been widely accepted for use in medical catheters [63-67].

$\mathrm{Wu}$ et al [68] developed a facile and green procedure for buildup of silver nanoparticles (AgNPs) on the central venous catheters (CVCs) surface. Inspired by mussel adhesive proteins, dopamine was used to form a thin polydopamine layer and induce AgNPs formation without additional reductants or stabilizers. The Staphylococcus aureusculture experiment was used to study the antibacterial properties. The cyto compatibility was assessed by water soluble tetrazolium salts (WST-1) assay, fluorescence staining, and scanning electron microscopy analysis. They evaluated the antibacterial activity dependent on the AgNPs dose. The high dose of AgNPs showed excellent antibacterial activity while associated with increased cytotoxicity. The appropriate density of AgNPs coated CVCs could exhibit improved biocompatibility and maintained evident sterilization effect. It is promising to design mussel-inspired silver releasing CVCs with both significant antimicrobial efficacy and appropriate biological property. Recently, Meera Divya et al [69], examined the biogenic synthesis and effect of silver nanoparticles to combat catheter-related urinary tract infections. The authors synthesized ecofriendly AgNPs from coral-associated bacteria. A total of 57 coral bacterial isolates were screened and the isolate MGL- D10 was selected for synthesizing AgNPs. The synthesized AgNPs MGL- D10 coated on catheters effectively inhibited the growth and biofilm formation of UTI causing pathogens.

\subsubsection{Bone cement}

Antibacterial activity of plain poly (methyl methacrylate) bone cement loaded with different NSP concentrations in vitro was evaluated by Alt et al, and found that $1 \%$ of bone cement-loaded nanosilver completely inhibited the proliferation of Staphylococcus epidermidis, methicillin-resistant $S$. epidermidis, and methicillinresistant $S$. aureus. Joint replacement components were fabricated by adding nanoparticles to ultra high molecular weight polyethylene and found that nanoparticles drastically reduced the wear and tear of the polymer [70, 71]. Russo et al studied the mechanical and antibacterial activity of polymethyl methacrylate (PMMA) -based bone cement loaded with gold nanoparticles. They demonstrated that nanocomposite cements with a specific concentration of gold nanoparticles improved the punching performance and antibacterial activity. However, critical aspects were found in the optimization of the nanocomposite bone cement [72].

Lithium carbonate nanoparticles were synthesized in presence of organic capping agents. In vitro tests showed that nanoparticle concentrations up to $600 / \mu \mathrm{g} / \mathrm{mL}$ do not disturb cell viability and promote the osteogenic differentiation of stem cells by $\mathrm{Li}^{+}$ions $(9.7 / \mathrm{mM})$ leached from the nanoparticles. This material may be useful for bone repair applications [73].

\subsubsection{Dental materials}

When nanoparticles are incorporated with resin composite, the material gives long-term inhibitory effect against Streptococcus mutans [74]. When incorporating nanoparticles in resin composite, endodontic filling 
materials and dental adhesives provide significantly enhanced anti bactericidal effect against oral Streptococci, Streptococcus milleri, S. aureus, and Enterococcus faecalis and thus enabling their use in orthodontic treatments [7577].

Leont'ev et.al., [78] developed a promising mouth rinse and other antibacterial drugs based on aqueous solutions of metal and metal oxide based semiconducting nanomaterials. The microbiological studies are carried out with the dental plaque microflora and aqueous solutions of $\mathrm{Fe}_{3} \mathrm{O}_{4}, \mathrm{SnO}, \mathrm{ZnO}, \mathrm{Ag}$, and $\mathrm{Cu}$ nanoparticles $10-100 \mathrm{~nm}$ in size and with a mass concentration of $1.53-10.12 \mathrm{mg} / \mathrm{L}$. The study of the effect of colloid solutions on the culture of dental plaque microflora shows that the antibacterial properties predominantly depend on the chemical composition of the particles of the dispersed phase.

Zunita et.al., [79] claims that the modified membrane using a metal oxide nanoparticles has better antifouling properties and also improved other properties such as mechanical strength, water flux, hydrophilicity, permeability, porosity, and rejection tendency. On another view Acosta Torres et.al suggested that the Nanomedicine could increase aesthetic features and improve the mechanical properties of new prostheses through the use of nanopigments acting as antimicrobial reagents and reinforcing fibers, while also avoiding infection by microorganisms.

Gislain et.al., [80]studied Ceramic as well as silica-rich glass nanoparticles have been incorporated into commercially available resin composite to mimic the aesthetics characteristics of tooth structures, and to achieve excellent long-term physical and mechanical properties such as high strength, hardness and toughness, and wear resistance. However, the selection of the most appropriate restorative material, clinicians should take into consideration important factors such as results from long-term clinical studies, low risk for post-operative sensitivity, long-term retention of indirect prosthodontic restorations, and ability to seal margins.

\subsubsection{Bio-diagnosis}

Nanoparticles play a major role in bio-diagnosis viz., 1) nanoparticle array biosensor for clinical detection of serum, 2) nanoshells to locate cancer cells and destroy them through photothermal therapy, 3) to detect the interaction between amyloid $\beta$-derived diffusible ligands (ADDL) and the anti-ADDL antibody which leads to Alzheimer's disease [81-84]. Hariharan et.al. [85], carried out a series of electrochemical experiments for pure and PEG assisted tungsten oxide $\left(\mathrm{WO}_{3}\right)$ nanoparticles prepared by microwave irradiation method for l-dopa sensing application on a GC electrode. The results showed that the PEG assisted samples had high sensitivity and good selectivity when compared to that of surfactant free samples.

Jubete et.al., [86] built screen printed electrodes with mushroom tyrosinase immobilized in a photo cross linkable polymeric gel on the working electrode. Concentrations of L-Dopa and other catechols are proved to be detected in the range of $5 \times 10^{-7} \mathrm{M}$ to $1 \times 10^{-5} \mathrm{M}$. On the other hand, Navarrete et.al., [87] developed a methodology to deliver different dopant agents in order to increase the sensitivity and selectivity of $\mathrm{WO}_{3}$ nanowire gas sensors towards two specific gases. Furthermore, the nanostructure and gas sensing properties of these sensors have been characterized in order to know the suitability of the materials for sensing applications. Moreover, Naveenkumar et.al. [88] elaborated the various synthesizing methods, preparation of composites; fabrication and gas sensing utilization of graphene-based nanocomposites are depicted in detail.

\section{CONCLUSION}

To conclude, the development and applications of Nano Science and technology has widened the platforms of Physics, Chemistry, Biology, Biotechnology etc. Due to their much smaller size and large surface area modification possibilities, it has a greater scope in Nano materials and medical diagnosis technology. These technologies have a promising one to explore various puzzles of quantum mechanics along with the fundamental research in science and technology. The basic knowledge about the synthesis of some metal oxide based semiconducting Nano dimensional materials along with their applications in materials and medicine discussed in detail. Still, there are some remarkable drawbacks in Nano science and technology in reproducing the end products and to know the complete mechanism involving during the synthesis of the materials by various physical and chemical techniques that will be dealt in the forthcoming review article which may be the continuation of this present article.

\section{ACKNOWLEDGEMENT}

The authors wish to thank DST-FIST-137/2013 and UGC/SERO-2192, Government of India for providing financial support to carry out this work.

\section{REFERENCES}

[1]. Richard Feynman P., 1960. There's Plenty of Room at the Bottom. Engineering and Science, 23(5), 2236.

[2]. Li, L.S., Hu, J., and Alivistos, A.P., 2001. Band gap variation of size- and shape-controlled colloidal CdSe quantum rods. Nano Letters, 1(7), 349-351.

[3]. Byrappa K., Ohara, S., and Adschiri, T., 2008. Nanoparticles synthesis using supercritical fluid technology-Towards biomedical applications. Adv. Drug Deliv. Rev. 60, 299-327.

[4]. Alagarasi, A, 2013, Chapter - Introduction to Nanomaterials, Indian Institute of Technology Madras, 1-24.

[5]. Konrad, A., Herr, U., Tidecks, R. and Samwer, F., 2001. Luminescence of bulk and nanocrystalline cubic yttria. J. of Appl. Phys., 90(7), 3516-3523.

[6]. Rostislav, A. Andrievskii, 1994. The synthesis and properties of nanocrystalline refractory compounds. Russ. Chem. Rev., 63, 411-427.

[7]. Sharma, A.B., Sharma, M. and Pandey,R.K., 2009. Synthesis, Properties and Potential Applications of Semiconductor Quantum Particles. Asian Journal of Chemistry, 21(10), S033-038.

[8]. Gohil, S., Chandra, R., Chalke, B., Bose, S. \& Ayyub, P., 2007. Sputter deposition of self-organised nanoclusters through porous anodic alumina templates. J. Nanoscience Nanotech., 7, 641646.

[9]. Chang, W., Skandan, G., Hahn, H., Danforth, S.C. and Kear, B.H., 1994. Chemical vapor condensation of nanostructured ceramic powders. Nanostructured Materials, 4(3), 345- 351. 
[10]. Winterer, M. and Hahn, H., Metallkd, Z., 2003. Chemical Vapor Synthesis of Nanocrystalline Powders. Nanoceramics by Chemical Vapor Synthesis, 94, 1084-1090.

[11]. Konrad , A., Herr, U., Tidecks, R. and Samwer, F., 2001. Luminescence of bulk and nanocrystalline cubic yttria. J. of Appl. Phys., 90(7), 3516-3523.

[12]. Namita Rajput, 2015. Methods of Preparation of Nanoparticles - A Review, 7(4), 1806-1811

[13]. Bhargava, R.N., Gallagher, D., Hong, X. and Nurmikko, A., 1994. Optical properties of manganese-doped nanocrystals of ZnS. Physical Review Letters, 72, 416-419.

[14]. Geetha, M., Suguna, K., Anbarasan, P.M., Aroulmoji, V., 2014. Preparation and Characterisation of Tailored $\mathrm{TiO}_{2}$ nanoparticles Photoanode for Dye Sensitised Solar Cells, Int. J. Adv. Sci. Eng. 1(1) 1-5.

[15]. Lu, C.H. and Jagannathan, J., 2002. Cerium-iondoped yttrium aluminum garnet nanophosphors prepared through sol-gel pyrolysis for luminescent lighting. Applied Physics Letters, 80(19), 36083610.

[16]. Morita, M., Rau, D., Kajiyama, S., Sakurai, T., Baba, M. and Iwamura, M., 2004. Luminescence properties of nano-phosphors: metal-ion doped sol-gel silica glasses. Materials Science-Poland, 22(1), 5-15.

[17]. Gole, A., C.J. Murphy, 2004. Seed-mediated synthesis of gold nanorods: role of the size and nature of the seed. Chem. Mater., 16, 3633-3640.

[18]. Song, J.Y., B.S. Kim, 2008. Rapid biological synthesis of silver nanoparticles using plant leaf extracts. Bioproc. Biosyst. Eng. 32, 79-84.

[19]. Pathipati Usha Rani and Pala Rajasekharreddy, 2011. Green synthesis of silver-protein (core-shell) nanoparticles using Piper betle L. leaf extract and its ecotoxicological studies on Daphnia magna. Colloids and Surfaces A: Physicochem. Eng. Aspects, 389, 188-194.

[20]. Krishnan Vijayaraghavan and S. P. Kamala Nalini, 2010. Biotemplates in the green synthesis of silver nanoparticles. Biotechnol. J., 5, 1098-1110.

[21]. Klaus, T., R. Joerger, E. Olsson, C.G. Granqvist, 1999. Silver-based crystalline nanoparticles, microbially fabricated. J Proc Natl Acad Sci USA, 96, 1361113614.

[22]. Nair, B., T. Pradeep, 2002. Coalescence of nanoclusters and formation of submicron crystallites assisted by Lactobacillus strains. Cryst Growth Des, 2, 293-298.

[23]. Konishi, Y., T. Uruga, 2007. Bioreductive deposition of platinum nanoparticles on the bacterium Shewanella algae. J Biotechnol, 128, 648-653.

[24]. Willner, I., R. Baron, B. Willner, 2006. Growing metal nanoparticles by enzymes. J Adv Mater, 18, $1109-1120$

[25]. Vigneshwaran, N., N.M. Ashtaputre, P.V. Varadarajan, R.P. Nachane, K.M. Paraliker, R.H. Balasubramanya, 2007. Biological synthesis of silver nanoparticles using the fungus Aspergillus flavus. Mater Lett, 61, 1413-1418.

[26]. Shiv Shankar Sangaru, Akhilesh Ra, Balaprasad Ankamwar, Murali Sastry, 2004. Biological synthesis of triangular gold nanoprism. Nature materials, 3(7): 482-488.
[27]. Sathiya Priya, R., Geetha, D., Ramesh, P.S., 2015. Photocatalytic Activity of Plant Mediated Biosynthesized Silver Nano Particles using Methyl Blue under Natural Sunlight, Int. J. Adv. Sci. Eng. 2 (1) $22-25$

[28]. Ahmad, N., S. Sharma, V.N. Singh, S.F. Shamsi, A. Fatma, B.R, Mehta, 2011. Biosynthesis of silver nanoparticles from Desmodium triflorum: a novel approach towards weed utilization. Biotechnol Res Int, ID-454090, 1-8.

[29]. Sathiyapriya,R., Aroulmoji,V., Gnanendra,S., Geetha, D., Kalagadda Venkateswara, R., Vanga,R. , Si-Hyun Park, 2018. Silver nanoparticle synthesis from carica papaya and virtual screening for anti-dengue activity using molecular docking, Materials Research Express, 6(3) March 035028.

[30]. Jae, Y.S., S.K. Beom, 2009. Rapid biological synthesis of silver nanoparticles using plant leaf extracts. Bioprocess Biosyst Eng, 32, 79-84.

[31]. Huang, J., Q. Li, D. Sun, Y. Lu, Y. Su, X. Yang, H. Wang, Y. Wang, W. Shao, N. J. Hong and C. Chen, 2007. Biosynthesis of Silver and Gold Nanoparticles by Novel Sundried Cinnamomum camphora Leaf. Nanotechnology, 18(10), 105104-105115.

[32]. Lanone, S., Boczkowski, J., 2006. Biomedical applications and potential health risks of nanomaterials, Molecular mechanisms. Curr Mol Med, 6(6), 651-663.

[33]. Gaffet, E., 2011. Nanomaterials: a review of the definitions, applications, health effects. How to implement secure development, Nanomaterials (Personal Communication).

[34]. Maurizio Prato, 1997. Fullerene chemistry for materials science applications, J. Mater. Chem., 7(7), 1097-1109.

[35]. Tim Albes, Liang Xu, Jian Wang, Julia W. P. Hsu, Alessio Gagliardi, 2018. Origin of Photocurrent in Fullerene-Based Solar Cells, J. Phys. Chem. C, 122 (27), pp 15140-15148.

[36]. Thomas Abraham, Nanotechnology and Nano Materials - Applications and Global Market Analysis Innovative Research and Products (iRAP), Inc. P.O. Box 16760, Stamford, CT 06905, USA

[37]. Catalogue of cosmetic ingredients: https ://euon.echa.europa.eu/catalogue-ofcosmetic-ingredients

[38]. Marcus Lau, Friedrich Waag, Stephan Barcikowski, 2017. Direct Integration of Laser-Generated Nanoparticles into Transparent Nail Polish: The Plasmonic "Goldfinger", Ind. Eng. Chem. Res., 56 (12), pp 3291-3296.

[39]. Bulut, E., M.Ozacar, 2007. A Facile Aquous-Phase Route to Synthesis of Silver Nanoparticles and Nanosheets. Nano-TR IV. Nanoscience and Nanotechnology Conference, ITU, Istanbul, Turkey, June 178, 9-13.

[40]. Raj, S. and Jose, S. 2012. Nanotechnology in Cosmetic: Opportunities and Challenges. Journal of Pharmacy and Bioallied Sciences, 4, 186-193.

[41]. The 2011 Nanodermatology Society Position Statement on Sunscreens.

http://www.nanodermsociety.org/documents/pre ss/NDS_Sunscreen_Guidelines.pdf

[42]. Kokura, S., Handa, O., Takagi, T., Ishikawa, T., Naito, Y. and Yoshikawa, T. 2010. Silver Nanoparticles as a Safe Preservative for Use in Cosmetic. 
Nanomedicin: Nanotechnology, Biology, \& Medicine, 6, 570-574.

[43]. Campbell, C.S.J., Contreras-Rojas, L.R., DelgadoCharro, M.B. and Guy, R.H., 2012. Objective Assessment of Nanoparticle Disposition in Mammalian Skin after Topical Exposure. Journal of Controlled Release, 162, 201-207.

[44]. Zhang, M., 2013. Au Natural Nanoparticles Sun Protection. Cosmetic and Toiletries, 128, 440.

[45]. Sonia, S., Linda Jeeva Kumari, H., Ruckmani, K., Sivakumar, M., 2017. Antimicrobial and antioxidant potentials of biosynthesized colloidal zinc oxide nanoparticles for a fortified cold cream formulation: A potent nanocosmeceutical application, Materials Science \& Engineering C (In Press).

[46]. Marolt, T et al. 2011. Photocatalytic activity of anatase-containing facade coatings Surf Coat Tech, 206(6): 1355-1361.

[47]. Kunniger, T et al. (2014), Release and environment impact of silver nanoparticles and conventional organic biocides from coated wooden facades. Environ Pollut, 184, 464-471.

[48]. Zhou, SX., Wu, L., Sun, J., and Shen, W., 2002. The change of the properties of acrylic-based polyurethane via addition of nano-silica. Progress in Organic Coatings, 45(1): 33-42.

[49]. Kumar, S., Verma, N.K., Singla, M.L., 2011. Reflective properties of $\mathrm{ZnS}$ nanoparticle coatings. J Coat Technol Res, 8(2): 223-228.

[50]. Bellotti, N., Romagnoli, R., Quintero, C., DominguezWong, C., Ruiz, F., Deya, C., 2015. Nanoparticles as antifungal additives for indoor water borne paints, Progress in Organic Coatings, 86, 33-40.

[51]. Angel Yedra, Gonzalo Gutierrez-Somavilla, Carmen Manteca-Martinez, Marina Gonzalez-Barriuso, Laura Soriano, 2016, Conductive paints development through nanotechnology, Progress in Organic Coatings, 95,85-90.

[52]. Anand Kumari, Durability and Integrity of Nanoceramic based Implementations in Assorted Domains, International Journal of Computing and Business Research (IJCBR) Volume 7 Issue 1 May June 2017.

[53]. Pawan Kumar, Brijnandan S Dehiya and Anil Sindhu, Bioceramics for Hard Tissue Engineering Applications: A Review, International Journal of Applied Engineering Research, 4562, 13, 5 (2018), 2744-2752

[54]. Rosanna Gonzalez-McQuire, DavidGreen, DominicWalsh, SimonHall, Jean-YvesChane-Ching, Richard O.C.Oreffo, 2005. Fabrication of hydroxyapatite sponges by dextran sulphate/amino acid templating, Biomaterials, 26(33), November 6652-6656.

[55]. Byko, M., 2005. From Electric Corsets to SelfCleaning Pants: The Materials Science and Engineering of Textiles. 57(7), 14-18.

[56]. Som, C et al. (2011), Environmental and health effects of nanomaterials in nanotextiles and façade coatings. Environ Int, 37(6): 1131-1142.

[57]. Windler, L et al. 2013. Comparative Evaluation of Antimicrobials for Textile Applications. Environ Int, $53,62-73$.

[58]. Moustaf M.G. Foudaa, E.S. Abdel-Halima, Salem S. Al-Deyaba, 2013. Antibacterial modification of cotton using nanotechnology, Carbohydrate Polymers 92, 943-954.

[59]. Liangpeng Ge, Qingtao Li, Meng Wang, Malcolm Xing, 2014. Nanosilver particles in medical applications: Synthesis, performance, and toxicity, International Journal of Nanomedicine 9(1):23992407

[60]. Burd, A., Kwok, C.H., Hung, S.C., 2007. A comparative study of the cytotoxicity of silverbased dressings in monolayer cell, tissue explant, and animal models, Wound Repair and Regeneration, 15(1), 94-104.

[61]. Singh R, Singh D.2014. Chitin membranes containing silver nanoparticles for wound dressing application. Int Wound J. Jun; 11(3):264-8.

[62]. Yadie Yang., Hong Hu.2015. A Review on Antimicrobial Silver Absorbent Wound Dressings Applied to Exuding Wounds, J Microb Biochem Technol, 7(4) 228-233

[63]. Chaloupka K, Malam Y, Seifalian AM. 2010. Nanosilver as a new generation of nanoproduct in biomedical applications. Trends Biotechnol., 28(11):580-588.

[64]. Marek Konop, Tatsiana Damps, Aleksandra Misicka, and Lidia Rudnicka, 2016. Certain Aspects of Silver and Silver Nanoparticles in Wound Care: A Minireview, Journal of Nanomaterials, 7614753, 10.

[65]. Yadie Yang., Hong Hu.2015. A Review on Antimicrobial Silver Absorbent Wound Dressings Applied to Exuding Wounds, J Microb Biochem Technol, 7(4) 228-233.

[66]. Rita Singh, Durgeshwer Singh, 2012. Chitin membranes containing silver nanoparticles for wound dressing application, Int Wound J;

[67]. Yadie Yang and Hong $\mathrm{Hu}, 2015$. A Review on Antimicrobial Silver Absorbent Wound Dressings Applied to Exuding Wounds, J Microb Biochem Technol, 7:4.

[68]. Ke Wu, Yun Yang, Yanmei Zhang, Jiexi Deng, and Changjian Lin, 2015. Antimicrobial activity and cytocompatibility of silver nanoparticles coated catheters via a biomimetic surface functionalization strategy, Int J Nanomedicine. 10: 7241-7252.

[69]. Meera Divya, George Seghalkiran, Saqib Hassan, Joseph Selvin, 2019. Biogenic synthesis and effect of silver nanoparticles (AgNPs) to combat catheterrelated urinary tract infections, Biocatalysis and Agricultural Biotechnology, 18, March 101037.

[70]. Alt V, Bechert T, Steinrücke P, et al. 2004. An in vitro assessment of the antibacterial properties and cytotoxicity of nanoparticulate silver bone cement. Biomaterials. 25(18):4383-4391.

[71]. Morley KS, Webb PB, Tokareva NV, et al. 2007. Synthesis and characterization of advanced UHMWPE/silver nanocomposites for biomedical applications. Eur Polym J. 43(2):307-314.

[72]. Russo,T., Gloria, A., De Santis, R., D'Amora,U., Balato,G., Vollaro,A., Oliviero,O., Improta,G., Triassi,M., Ambrosio,L., 2017. Preliminary focus on the mechanical and antibacterial activity of a PMMA-based bone cement loaded with gold nanoparticles, Bioactive Materials, 2(3), 156-161. 
[73]. Cristian Covarrubias, Juan Pablo Durán, Miguel Maureira, 2018. Facile synthesis of lithium carbonate nanoparticles with potential properties for bone repair applications. Material Letters, 2019, 205-208.

[74]. Yoshida K, Tanagawa M, Matsumoto S, Yamada T, Atsuta M. 1999. Antibacterial activity of resin composites with silver-containing materials. Eur J Oral Sci. 107(4):290-296.

[75]. Yamamoto K, Ohashi S, Aono M, Kokubo T, Yamada I, Yamauchi J. 1996. Antibacterial activity of silver ions implanted in $\mathrm{SiO} 2$ filler on oral streptococci. Dent Mater. 12(4):227-229.

[76]. Magalhães APR, Santos LB, Lopes LG, et al. 2012. Nanosilver application in dental cements. ISRN Nanotechnology. 2012:1-6.

[77]. Ahn SJ, Lee SJ, Kook JK, Lim BS. 2009. Experimental antimicrobial orthodontic adhesives using nanofillers and silver nanoparticles. Dent Mater. 25(2):206-213.

[78]. Leont'ev, V. K., Pogorel'skii, I. P., Frolov, G. A., Karasenkov Ya. N., Gusev, A. A., Latuta, $\begin{array}{ll}\text { N. V., Borozdkin, } \quad \text { L.L., Stefantsova, } & \text { D. S. } 2018 .\end{array}$ Antibacterial Properties of Aqueous Colloid Solutions of Metal and Metal Oxide Nanoparticles against Dental Plaque Bacteria, Nanotechnologies in Russia, 13 (3-4), 195-198.

[79]. Zunita, M., Makertihartha,I.G.B.N., Saputra, F.A., Syaifi,Y.S., Wenten, I.G., 2018. Metal Oxide based Antibacterial Membrane, IOP Conf. Series: Materials Science and Engineering 395, 012021.

[80]. Gislaine C. Padovani, Victor P. Feitosa, Salvatore Sauro,Franklin R. Tay, Gabriela Durán, Amauri J. Paula, and Nelson Durán,2015. Advances in Dental Materials through Nanotechnology: Facts, Perspectives and Toxicological Aspects, Trends in Biotechnology, 33 (11), November, 621-636.
[81]. Haes AJ, Van Duyne RP. 2002. A nanoscale optical biosensor: sensitivity and selectivity of an approach based on the localized surface plasmon resonance spectroscopy of triangular silver nanoparticles. J Am Chem Soc. 124(35):1059610604.

[82]. Zhou W, Ma Y, Yang H, Ding Y, Luo X. 2011. A labelfree biosensor based on silver nanoparticles array for clinical detection of serum p53 in head and neck squamous cell carcinoma. Int J Nanomedicine. 6:381-386.

[83]. Loo C, Lowery A, Halas N, West J, Drezek R., 2005. Immunotargeted nanoshells for integrated cancer imaging and therapy. Nano Lett., 5(4):709-711.

[84]. Haes AJ, Hall WP, Chang L, Klein WL, Van Duyne RP. 2004. A localized surface plasmon resonance biosensor: first steps toward an assay for Alzheimer's disease. Nano Lett. 4(6):1029-1034.

[85]. Hariharan V, Radhakrishnan S, Parthibavarman M, Dhilipkumar R, Sekar C, Synthesis of polyethylene glycol (PEG) assisted tungsten oxide $\left(\mathrm{WO}_{3}\right)$ nanoparticles for l-dopa bio-sensing applications, Talanta, 85: 2166 - 2174.

[86]. Elena Jubete, Estibaliz Ochoteco, Iraida Loinaz, Jose A.Pomposo and Hans Grande, 2008. Electrochemical biosensor development for detection of L-dopa levels in plasma during Parkinson illness, IEEE SENSORS Conference

[87]. Navarrete, È.; Bittencourt, C.; Llobet, E., 2018. Gas Sensing Properties of $\mathrm{WO}_{3}$ Nanowires Decorated with Iridium Oxide Nanoparticles, Proceedings, 2, 964.

[88]. Naveen kumar, J.R., Shrinivasa Mayya, D., Savitha, M.B., Prasda, P., 2018. Graphene-Based Metal Oxide Nanocomposites for Gas Sensing Application, International journal of applied engineering and Management letters, 2(2), 98-115. 